\title{
PENDIDIKAN KEWIRAUSAHAAN BERWAWASAN GENDER BAGI PENGELOLA UNIT USAHA BUMDES DESA KARANG BUNGA, KECAMATAN MANDASTANA, KABUPATEN BARITO KUALA PROVINSI KALIMANTAN SELATAN
}

\author{
Nurhikmah $^{1^{*}}$, Devi Rusvitawati ${ }^{2}$, \\ Firda Rezky Herryawan ${ }^{3}$, Chumaidi $^{4}$, Mia $^{4}$, Tiara Agustina ${ }^{5}$ \\ ${ }^{12345}$ STIMI Banjarmasin \\ *Email ; nurhikmahdardi09@gmail.com
}

\begin{abstract}
ABSTRAK
Pendidikan Kewirausahaan Berwawasan Gender bagi Pengelola Unit Usaha Bumdes Desa Karang Bunga, Kecamatan Mandastana, Kabupaten Batola-Kalsel. Adapun tujuan dari kegiatan ini adalah untuk mewujudkan pemberdayaan masyarakat khususnya kaum perempuan di bidang ekonomi melalui penumbuhan dan pengembangan kegiatan keterampilan sehingga mempunyai kemampuan dan daya saing dalam lapangan kerja maupun usaha ekonomi. Metode yang digunakan dalam pelaksanaan ini menggunakan metode PRA (Partisipetory Rulai Apraisah). Hasil dari kegiatan ini bahwa sebagaian masyarakat Desa Karang Bunga, Kecamatan Mandastana, Kabupaten Batola-Kalsel khususnya kaum perempuan memiliki kemampuan dasar tentang kewirausahaan sebagai modal dasar mencari kerja ataupun membuka usaha baru, serta terbentuknya komunitas masyarakat untuk membuka usaha baru berbasis potensi local yang berwawasan gender.

Kata kunci: Pendidikan Kewirausahaan Berwawasan Gender (PKBG).

\section{EDUCATION OF GENDER-BASED ENTREPRENEURSHIP FOR MANAGEMENT UNIT BUSINESS UNIT VILLAGE KARANG BUNGA, SUBDISTRICT MANDASTANA, DISTRICT BARITO KUALA PROVINCE KALIMANTAN SELATAN}

\begin{abstract}
A Gender-Based Entrepreneurship Education for BUMDes administrators of Karang Bunga Village, Mandastana District, Barito Kuala in South Kalimantan. This activity aims to build the community empowerment, especially women in the economic field through the growth and development of skills activities so that they have the ability and competitiveness in employment and economic ventures. The PRA (Participatory Rulai Apraisah) method had been used in implementing this activity. The results reveal that some people of Karang Bunga Village, Mandastana District, Barito Kuala in South Kalimantan, especially women have basic skills about entrepreneurship as the basic capital to find work or open a new business, and there is a community formation to open new businesses based on local potentials with a gender perspective.
\end{abstract}

Keywords: Gender-Based Entrepreneurship Education

\section{PENDAHULUAN}

Pembangunan Pemberdayaan Perempuan (PP) dan Kesejahteraan Perlindungan Anak (KPA) yang tertuang dalam Rencana Pembangunan Jangka Panjang Menengah Nasional (RPJMN) 20152021, disebutkan bahwa salah satu dari 5 (lima) sasaran pokok yang berkaitan dengan agenda mewujudkan Indonesia yang adil dan demokratis adalah terjaminnya Keadilan dan Kesetaraan Gender dalam berbagai bidang pembangunan yang tercermin dalam berbagai peraturan perundang-undangan. Program pembangunan dan kebijakan public. Selanjutnya menyatakan meningkatkan tarap pendidikan dan layanan kesehatan serta bidang pembangunan lainnya, untuk mempertinggi kualitas hidup dan sumberdaya kaum perempuan.

Untuk mewujudkan anah yang tercantum dalam RPJMN tersebut diatas, langkah positif dari pemerintah Indonesia yang sebelumnya telah menerbitkan berbagai peraturan perundang-undangan dan kebijakan public dalam kaitan dengan Kesetaraan dan Keadilan Gender (KKG) dan Kesejahteraan dan Perlindungan Anak (KPA) seperti seperti Undang-Undang Hak Asasi Manusia Nomor 39 Tahun 
BAKTI BANUA : Jurnal Pengabdian Kepada Masyarakat

Volume 1 No. 1 Mei 2020

https://ejurnal.stimi-bjm.ac.id/index.php/BBJM/

1999, Undang-Undang Perlindungan Anak Nomor 23 Tahun 2002 Jo Undang-Undang Nomor 35 tahun 2014 tentang Perubahan atas Undang_undang Nomor 23 Tahun 2002 tentang Perlindungan Anak, Undang-Undang Nomor 23 Tahun 2004 tentang Penghapusan Kekerasan dalam Rumah Tangga (PKDRT) serta Intruksi Presiden Nomor 9 Tahun 2000 tentang Pengarusutamaan Gender (PUG) dalam Pembangunan Nasional dan terakhir Undang-Undang Nomor 21 Tahun 2007 tentang Tindak Pidana Penghapusan Perdaganagan Orang.

Berdasarkan Undang-Undang Nomor 23 Tahun 2014 tentang Pemerintah Daerah, mengatur tentang Otonomi Daerah yang memberikan kewenangan luas, nyata dan bertanggung jawab kepada pemerintah kota dan kabupaten. Otonomi Daerah dilaksanakan dengan prinsip-prinsip demokratis dan memperhatikan keanekaragaman permasalahan yang ada di daerah masing-masing. Otonomi daerah menjadikan peluang dan tantangan bagi pemerintah untuk berani mengambil inisiatif atau melakukan terobosan-terobosan dalam berbagai kebijaksanaan untuk mengsinergikan berbagai unsur dalam penanganan masalah perempuan dan anak.

Sejak diterbitkannya Instruksi Presiden Nomor 9 tahun 2000 dengan maksud dalam proses pembangunan sejak pelaksanaan, pemantauanh, evaluasi kebijakan pembangunan dengan mengintegrasikan gender ialah tidak lain agar kelompok-kelompok yang mengalami marjinalisasi khususnya perempuan dan anak mendapatkan keadilan, rasa aman dan perlindungan untuk mencapai KKG.

Berselang 19 (sembilan belas) tahun lamanya Instruksi Presiden Nomor 9 Tahun 2000, merupakan strategi untuk mempercepat tercapainya KKG, tetapi hasilnya masih jauh dari apa yang diharapkan. Berbagai factor yang melatarbelakangi tertatihnya proses menuju KKG, antara lain : 1) persepsi dan pemahaman para pengambil keputusan masih rendah; 2) sebelum tahun 2008 tentang kelembagaan yang membidangi perempuan dan anak berada pada eselon 3;3) budaya patriarkhi yang telah mengakar di masyarakat; 4) Era Otonomi daserah berimplikasi pada KKG; 5) tersedia data terpilah sangat terbatas, terkecuali pada dinas/badan yang secara khusus diprogramkan pembuatan data terpilah yang sepenuhnya didukung oleh pemerintah pusat. Fakta menunjukkan bahwa masih terdapat kesenjangan gender adri berbagai aspek kehidupan, diantaranya bidang pendidikan, kesehatan, politik, hukum dan ekonomi serta kemasyarakatan.

Posisi Kalsel tentang Indeks Pembangunan Manusia (IPM) 70,71 masih berada dibawah angka rata-rata nasional tahun 2018 berada pada peringfkat 22 dari 34 provinsi se-Indonesia (BPS,Kalsel). IPM Indonesia mencapai 71,39, berapa di peringkat 116 dari 171 negara di dunia.

Rendahnya kualitas hidup perempuan akan mempengaruhi kontribusi pada indeks Pembangunan Manusia/Human Development Indeks (HDI) di Kalimantan Selatan khususnya dan Indonesia pada umumnya terutama dibidang-bidang strategis seperti pendidikan, kesehatan dan ekonomi. Hasil laporan HDI tahun 2018 Provinsi Kalimantan Selatan 70,17\% tumbuh sekitar 0,75\% disbanding tahun 2017.

Tingkat Partisipasi Angkatan Kerja (TPAK) laki-laki lebih tinggi dari pada perempuan di kota dan di desa, menggambarkan bahwa terbukanya kesempatan untuk mamasuki dunia kerja secara aktif dan pencari kerja, sementara akses dan peran serta control perempuan sangat terbatas karena perempuan tugasnya mengurus rumah tangga, berdasarkan jenis kelamin terdapat perbedaan TPAK antara laki-laki dan perempuan, pada Pebruari 2018 TPAK laki-laki sebesar 83,01\% sedangkan perempuan hanya sebesar $55,44 \%$.

Atas dasar kenyataan tersebut di atas pemerintah Provinsi Kalimantan Selatan menetapkan kebijakan pembangunan untuk tahun 2016-2021 yang termuat dalam RPJMD sebagaimana termuat dalam Perda Nomor 7 Tahun 2016 tentang RPJMD Provinsi Kalimantan Selatan 2016-2021. Permasalahan perempuan di bidang ekonomi tidak terlepas dari kemiskinan pada umumnya adalah karena dampak keterbatasan kapasitas sumber daya manusia dalam hubungannya dengan wawasan, pengetahuan, keterampilan, etos kerja serta pola pikir dalam berusaha. Untuk itu perlu dikembangkan program pemberdayaan perempuan yang diarahkan dengan menitik beratkan pada pemberian bekal keterampilan bagi kaum perempuan untuk mampu memasuki lapangan kerja atau memulai usaha baru.

Dengan demikian pemberdayaan perempuan disektor ekonomi haruslah diarahkan pada peningkatan kemampuan dalam melaksanakan produksi dan distribusi yang mencakup manajemen usaha, manajemen rumah tangga, pemasaran, dan kemudahan memperoleh akses terhadap sumber daya yang dibutuhkan untuk melakukan usaha seperti akses informasi usaha, pasar dan permodalan. 
BAKTI BANUA : Jurnal Pengabdian Kepada Masyarakat

Volume 1 No. 1 Mei 2020

https://ejurnal.stimi-bjm.ac.id/index.php/BBJM/

Dalam kaitan tersebut di atas dan dalam rangka pemberdayaan perempuan tim pengabdian masyarakat STIMI Banjarmasin ingin turut berpartisipasi mengentasakan kemiskinan melalui program Pendidikan Kewirausahaan Berwawasan Gender bagi Pengelola Unit Usaha Bumdes Desa Karang Bunga, Kecamatan Mandastana, Kabupaten Batola-Kalsel

\section{KAJIAN LITERATUR \\ KKG Dan PUG Dalam Pemberdayaan Ekonomi Perempuan (Tim Pusat Studi Gender STIMI Banjarmasin)}

Dalam materi ini bertujuan agar peserta menyadari bahwa gender adalah bentukan social dan memperjelas perbedaan antara gender dan jenis kelamin selanjutnya diharapkan peserta nantinya juga menyadari tempat dan situasi dimana ketidaksetaraan antara perempuan dan laki-laki serta sejauhmana aspek ketidaksetaraan gender dapat lebih dikenal dan memahami pentingnya KKG dan PUG dalam pemberdayaan ekonomi perempuan.

\section{Pengertian}

Konsep gender mengacu pada pembedaan peran dan tanggung jawab antara laki-laki dan perempuan, serta terjadi akibat dari dan dapat berubah oleh keadaan social budaya masyarakat. Sedangkan Jenis kelamin mengacu pada perbedaan organ biologis laki-laki dan perempuan khusunya pada bagian reproduksi yang bersifat kodrati dan juga merupakan dimorfieme seksual yang pada manusia dikenal menjadi laki-laki dan perempuan.

Perbedaan antara gender dan jenis kelamin, 1) Jika jenis kelamin merupakan konstruksi biologis sedangkan gender merupakan suatu konstruksi social budaya; 2) Jika jenis kelamin itu sama saja dimana pun berada dan berasal, sedangkan gender bias tidak sama; 3) Jenis kelamin tidak dapat ditukar, sedangkan gender dapat dipertukarkan; 4) Jenis kelamin bersifat statis sedangkan gender bersifat dimanis; 5) jenis kelamin tidak tergantung waktu sedangkan gender tergantung waktu; 6) Jenis kelamin bersifat kodrat sedangkan gender bukan bersifat kodrati.

Kemudian apakah gender itu menjadi masalah ? Gender tidak menjadi masalah jika dilakukan secara adil dan menguntungkan kedua belah pihak, tetapi bias menjadi masalah jika salah satu jenis kelamin dibedakan derajatnya, salah satu jenis kelamin dianggap tidak mampu, salah satu jenis kelamin diperlakukan lebih rendah dan salah satu jenis kelamin mengalami ketidakadilan.

Manifestasi dari ketidakadilan gender antara lain berupa : 1) subordinasi ; 2) diskriminasi; 3) marjinalisasi 4) beban ganda; 5) subordinasi; dan 6) kekerasan.

Pelabelan masyarakat selama ini tentang laki-laki dan perempuan :

1) Sifat : laki-laki harus maskulin, perempuan harus feminism;

2) Fungsi : laki-laki harus menjalankan fungsi produktif, sedang perempuan harus menjalankan fungsi reproduktif;

3) Ruanglingkup : laki-laki harus bekerja diruang public sementara perempuan di ruang domestic;

4) Tanggung jawab : laki-laki harus bertanggung jwab menjadi pencari nafkah utama sementara perempuan pencari nafkah tambahan saja.

Mengapa perlu memperbincangkan KKG ? Karena :

- Masih ada diskriminasi \& ketidakadilan terhadap perempuan \& laki-laki;

- Perempuan tidak bisa berkembang - hanya diberi peran dalam urusan rumah tangga - tidak mendapat kesempatan / peluang utk peran-peran produktif;

- Laki-laki dibebani pekerjaan, tugas, tanggung jawab yang terlaluberat \& dituntut utk lebih mampu \& lebih kuat dalam banyak hal;

- Anak perempuan tidak mendapat pendidikan formal yang sama tingginya seperti yang diterima anak laki-laki dengan berbagai macam alas an;

- Perempuan terrgantung pada nafkah suami sehingga tidak memiliki keterampilan/ pengalaman yang sebanding dgn laki-laki;

- Perempuan melakukan pekerjaan ganda

- Potensi \& bakat yang dimiliki perempuan/ laki-laki kurang mendapatkan wadahnya. 
BAKTI BANUA : Jurnal Pengabdian Kepada Masyarakat

Volume 1 No. 1 Mei 2020

https://ejurnal.stimi-bjm.ac.id/index.php/BBJM/

Apakah KKG itu ? Keadilan gender (gender equity) yaitu perlakuan yang adil yang diberikan baik kepada perempuan maupun laki-laki dan Kesetaraan gender (gender equality) yaitu laki-laki dan perempuan menikmati status yang samadan memiliki kondisi yang sama utk menggunakan hakhaknya \& kemampuannya secara penuh dalam memberikan kontribusinya kepada pembangunan, politik, ekonomi \& sosbud.

Adapun indicator keberhasilan KKG ialah :

1) Akses yang sama atau setara antara laki-laki dan perempuan.

2) Partisipasi yang sama atau setara antara laki-laki dan perempuan.

3) Kontrol yang sama atau setara atas sumber-sumber daya yang ada.

4) Manfaat yang sama atau setara atas atas hasil-hasil pembangunan.

Untuk memastikan KKG maka diperlukan adanya sistem dokumentasi data yang memilahkan antara laki-laki dan perempuan dalam suatu masyarakat.

Penggunaan cara-cara yang partisipatif, fair dan apresiatif, baik bagi laki-laki maupun perempuan, dalam proses-proses pembangunan dan bermasyarakat.

Landasan Hukum Pelaksanaan PUG :

1) UU No. 7/1984 tentang Penghapusan Segala Bentuk Diskriminasi thd Wanita;

2) Keppres No. 9/2000 tentang Pelaksanaan PUG dalam Pembangunan Nasional;

3) UU No. 32/2004 tentang Pemda Jo UU No. 23/2014;

4) Permendagri No. 15/2008 tentang Pedoman umum pelaksanaan PUG di daerah Jo Permendagri No. 67/2011 tentang Pedoman Umum Pelaksanaan PUG di Daerah;

5) Peraturan Daerah Provinsi Kalimantan Selatan Nomor 3 Tahun 2009 tentang Rencana Pembangunan Jangka Panjang Daerah Provinsi Kalimantan Selatan Tahun 2007-2025;

6) Perda No. 5/2009 tentang PUG dalam Pembangunan Daerah;

7) Peraturan Daerah Provinsi Kalimantan Selatan Nomor 11 Tahun 2018 tentang Pemberdayaan Perempuan dan Perlindungan Anak.

Pengarusutamaan Gender (PUG) adalah salah satu strategi pembangunan yang dilakukan utk mencapai kesetaraan \& keadilan gender, melalui pengintegrasian pengalaman, aspirasi, kebutuhan \& permasalahan laki-laki \& perempuan ke dalam perencanaan, pelaksaan, pemantauan \& evaluasi dari seluruh kebijakan, proyek \& kegiatan di berbagai bidang kehidupan \& pembangunan.

Tujuan Pengarusutamaan Gender (PUG) adalah untuk memastikan apakah perempuan dan laki-laki telah mempunyai akses yang sama dan dan memiliki partisipasi yang sama serta memiliki control yang sama serta memperoleh manfaat yang sama.

\section{KKG dan PUG dalam SDGs}

Target utamanya adalah Mencapai kesetaraan gender dan memberdayakan kaum ibu dan perempuan. Pemberdayaan ekonomi perempuan sebagai salah satu pintu masuk perempuan keluar dari kemiskinan yang merupakan target pertama dari SDGs yaitu Tidak ada kemiskinan dalam bentuk apapun di seluruh penjuru dunia.

\section{Kemandirian Ekonomi dan Nirkekerasan Terhadap Perempuan}

Menghilangkan gender-based violence sebagai salah satu prioritas poin kesetaraan gender dalam kerangka SDGs dapat didorong salah satunya melalui upaya pemberdayaan ekonomi.

Kemandirian ekonomi adalah suatu kondisi yang harus dimiliki oleh setiap perempuan agar dapat terlepas dari ketergantungan mutlak terhadap pasangannya. Kondisi ketergantungan tersebut seringkali memposisikan perempuan berada pada posisi yang lemah dan sebaliknya pihak suami yang lebih berkuasa.

\section{Kebijakan untuk Pemberdayaan Ekonomi Perempuan}

Kementerian Pemberdayaan Perempuan dan Perlindungan Anak (Kemen PPPA) memiliki program prioritas, yakni Three Ends.

Program Three Ends ini bertujuan untuk mengakhiri permasalahan yang dihadapi kaum perempuan dan anak, yakni : 
BAKTI BANUA : Jurnal Pengabdian Kepada Masyarakat

Volume 1 No. 1 Mei 2020

https://ejurnal.stimi-bjm.ac.id/index.php/BBJM/

(1) Akhiri kekerasan terhadap perempuan dan anak;

(2) Akhiri perdagangan orang; dan

3) Akhiri ketidakadilan akses ekonomi terhadap perempuan.

Program ini diharapkan dapat membangun kepedulian dan kesadaran masyarakat akan pentingnya perlindungan perempuan dan anak sebagai isu prioritas demi mewujudkan Indonesia yang ramah bagi perempuan dan tumbuh kembang anak. Guna mewujudkan tujuan ketiga program three ends, yakni mengakhiri ketidakdilan akses ekonomi terhadap perempuan, Kemen PPPA sejak 2016 melaksanakan kegiatan Pemberdayaan Ekonomi Perempuan melalui pengembangan Pelaku Industri Rumahan atau IR. Industri Rumahan (IR) yaitu suatu industri skala mikro.

Mengapa pemberdayaan ekonomi ini penting dilakukan kepada para perempuan?

Berdasarkan data secara nasional, usaha mikro memberikan kontribusi sebesar 30,25\% bagi produk domestik bruto, sebagian besar dilakukan oleh perempuan.

Kepala rumah tangga perempuan yang berusaha sendiri sebesar 37,91\%, lebih besar dibandingkan laki-laki sebesar $22,34 \%$, dan perempuan yang berusaha sendiri ini sebagian besar ada di usaha mikro. Upaya pemberdayaan ekonomi perempuan sudah banyak dilakukan oleh berbagai sektor, namun belum sepenuhnya terintegrasi dalam membantu pelaku Industri Rumahan skala mikro.

Kesempatan Perempuan (peluang yang berasal dari luar pribadi) :

1) Berkembangnya keasadaran masyarakat tentang peran ekonomi perempuan, yang berarti mereka mau menghargai dan memberi kesempatan pada perempuan unt berkembang secara pribadi.

2) Makin banyak perempuan yang sadar akan potensinya, sehingga muncul pemimpin perempuan diberbagai bidang.

3) Terbukanya kesempatan bagi perempuan untuk meningkatkan pengetahuan melalui pendidikan.

4) Adanya jalinan kerjasama yang makin kuat bagi perkembangan perempuan, sehingga perempuan makin percaya diri bahwa mereka tidak sendiri.

Tantangan Kebijakan untuk Pemberdayaan Perempuan :

1) Hingga saat ini belum ada perUU yang secara khusus mengatur tentang pemberdayaan ekonomi perempuan.

Misalnya :

UU Perkawinan No.1/1974 tentang Perkawinan, (yang cenderung merugikan perempuan dalam kaitannya dengan collateral .

UU No. 20/2008 tentang UMKM, belum secara maksimal semua UMK perempuan pelaku usaha mikro sudahkah merasa mudah memperoleh permodalan dr perbankan?

Untuk itulah dirasa sangat diperlukan pendidikan kewirausahaan berwawasan gender untuk meningkatkan kualitas dan tarap hidup masyarakat khususnya kaum perempuan. Kewirausahan sendiri adalah suatu sikap, jiwa dan kemampuan untuk menciptakan sesuatu yang baru yang sangat bernilai dan berguna bagi dirinya dan orang lain. Kewirausahaan merupakan sikap mental dan jiwa yang selalu aktif atau kreatif berdaya, bercipta, berkarya dan bersahaja dan berusaha dalam rangka meningkatkan pendapatan dalam kegiatan usahanya.

Pendidikan kewirausahaan bertujuan untuk membentuk manusia secara utuh (holistik), sebagai insan yang memiliki karakter, pemahaman dan ketrampilan sebagai wirausaha. Pada dasarnya, pendidikan kewirausahaan dapat diimplementasikan secara terpadu dengan kegiatan-kegiatan pendidikan di formal dan non formal dimasyarakat. Kegiatan pendidikan kewirausahaan adalah merupakan salah satu wujud dari kegiatan pemberdayaan perempuan dalam rangka PUG di daerah.

Namun ada beberapa hal yang perlu menjadi bahan telaah terkait pemberdayaan perempuan : 
1) Perempuan terpinggirkan (termarjinalisasi) sebagai pelaku ekonomi, terkait dgn ketidaksetaraan struktural yang mengakibatkan permuan mengalami ketidaknyamanan secara ekonomi dibanding laki-laki.

2) Pemberdayaan ekonomi jg berkontribusi terhadap pengurangan kekerasan berbasis gender, meningkatkan kesempatan perencanaan keluarga.

3) Terdapat hubungan positif dgn kesehatan dan pendidikan anak.

4) Jika perempuan diberi kesempatan unt mandiri secara ekonomi, mk ia tidak hanya membantu dirinya keluar dr kemiskinan tp jg keluarganya, krn sebagian besar adalah unt memenuhi kubutuhan hidup keluarga.

Pemberdayaan perempuan harus mengupayakan para perempuan untuk secara aktif melakukan perubahan unt dirinya. Perubahan itu dimaksudkan agar perempuan nantinya memiliki bargaining power, baik dalam lingkup domestik, maupun publik. Dengan demikian dapat mengangkat kualitas hidupnya, baik dalam konteks ekonomi, sosial. Pemberdayaan perempuan juga harus didukung dgn kebijakan yang lebih memberi ruang bg perempuan untk terlibat dalam proses perumusan kebijakan sehingga perempuan mampu mengartikulasikan kepentingan dalam berbagai kebijakan.

\section{Strategi Perencanaan Pembangunan Gender di Kabupaten Barito Kuala}

(Siti Rabiatul Adawiyah dari Dinas Pengendalian Penduduk, KB dan Pemberdayaan Perempuan dan Anak)

Sebagaimana yang diatur dalam RPJMD Kabupaten Barito Kuala 2017-2022, Visi kab. BATOLA SETARA (satu kata satu rasa membangun desa menata kota menuju masyarakat sejahtera). Melalui Misi :

1) Mengintegrasikan infrastruktur wilayah yang mendukung kemandirian desa dan penataan perkotaan;

2) Meningkatkan perekonomian masyarakat melalui teknologi berbasis pertanian;

3) Meningkatkan kualitas kataqwaan, kecerdasan, kesehatan dan profesionalitas sumberdaya manusia;

4) Memantapkan tata kelola pemerintahan yang terbuka dan melayani.

Untuk mencapai misi ketiga diatas maka sasaran yang ingin dicapai :

1) Meningkatnya kualitas pendidikan dan derajat kesehatan masyarakat;

2) Meningkatnya kesejahteraan dan daya saing masyarakat;

Dalam rangka mencapai peningkatan kualitas pendidikan dan derajat kesehatan masyarakat maka ada beberapa indicator penentu yaitu :

1) Angka rata rata lama sekolah (rls);

2) Angka harapan hidup.

Sedangkan untuk meningkatnya kesejahteraan dan daya saing masyarakat, indikatornya ialah :

1) Tingkat pengangguran:

- Sosial;

- Tenaga kerja;

- Pembinaan masy dan desa;

- Transmigrasi.

2) Tingkat kemiskinan :

- Pendidikan;

- Kesehatan;

- Pemberdayaan masy dan desa;

- Koperasi dan UKM;

- Pangan;

- Kependudukan \& Capil;

- Kerajinan \& perikanan;

- Pertanian.

Adapun SKTD terkait yang berhubungan dengan indikator di atas ialah :

Dinas Pendidikan, Dinas Kesehatan, Rumah Sakit, Dinas Pemberdayaan Masy Desa, Dinas Koperasi PP, Disdukcapil, Dinas Pertanian dan Perikanan serta Dinas Peternakan. 
BAKTI BANUA : Jurnal Pengabdian Kepada Masyarakat

Volume 1 No. 1 Mei 2020

https://ejurnal.stimi-bjm.ac.id/index.php/BBJM/

Permendagri 67/2011:

Pemda berkewajiban menyusun kebijakan, program, dan kegiatan pembangunan berperspektif gender yang dituangkan dalam RPJMD, Renstra SKPD, dan Renja SKPD (Ayat (1) psl 4).

* Penyusunan kebijakan, program, dan kegiatan pembangunan berperspektif gender sbgmn pada ayat (1) dilakukan melalui analisis gender (ayat (2) psl 4). Analisis gender dapat menggunakan GAP atau analisis gender lainnya.

Pasal 5A (merupakan tambahan yang fundamental):

* Hasil analisis gender sbgmn dimaksud dalam psl 5 ayat (3) dituangkan dalam penyusunan GBS;

* Hasil analisis gender yang terdapat dalam GBS menjadi dasar SKPD dalam menyusun kerangka acuan kegiatan dan merupakan bagian yang tak terpisahkan dgn dokumen RKA/DPA SKPD.

RPJMN 2015-2019 (Kepres No 2/2015) :

1. Meningkatkan kualitas hidup dan peran perempuan di berbagai bidang pembangunan;

2. Meningkatkan perlindungan perempuan dari berbagai tindak kekerasan, termasuk Tindak Pidana Perdagangan Orang;

3. Meningkatkan kapasitas kelembagaan PUG dan kelembagaan perlindungan perempuan dari berbagai tindak kekerasan.

Kemudian target RPJM 2015-2019 sebagaimana keppres Nomor 2/2015 ialah :

1. Akhiri kekerasan terhadap perempuan dan anak;

2. Akhiri Perdagangan Manusia;

3. Akhiri kesenjangan ekonomi.

Yang kita kenal sebagai Program 3end, dimana untuk target ketiga yaitu mengakhiri masalah kesenjangan ekonomi, hal ini sangat terkait dengan upaya pemberdayaan perempuan dibidang kewirausahaan.

\section{METODE PENGABDIAN}

Metode yang digunakan dalam pelaksanaan ini menggunakan metode PRA (Partisipetory Rulai Apraisah) yaitu metode memungkan masyarakat desa untuk saling berbagi, serta meningkatkan pengetahuan serta menggali potensi dsa agar mampu membuat rencan dan tindakan yang nyata untuk meningkatkan Sumber Daya Manusia dan Sumber Daya Alam di desa. Pada metode pelaksana kegiatan Pengabdian Pada Masyarakat ini menggunakan teknik Komunikasi, Informasi dan Edukasi (KIE) meliputi Sosialisasi, Workshop, Focus Group Discussion (FGD), Diklat serta Advokasi/Pendampingan kepada PIHAK KEDUA untuk Kegiatan Pemberdayaan Masyarakat khususnya perempuan melaui Pendidikan Kewirausahaan Berwawasan Gender (PKBG) Berbasis Potensi Lokal bagi Unit Usaha BUMDes Desa Karang Bunga Kecamatan Mandastana, Kabupaten Barito Kuala.

\section{HASIL PENGABDIAN DAN PEMBAHASAN}

Kegiatan PKBG dilaksanakan pada hari Senin, tanggal 30 September 2019, bertempat di Aula BUMDes Desa Karang Bunga, Kecamatan Mandastana, Kabupaten Barito Kuala. Bertindak selaku narasumber dalam kegiatan tersebut ialah :

- Tim Pusat Studi Gender (PSG) STIMI Banjarmasin, dengan judul makalah KKG Dan PUG Dalam Pemberdayaan Ekonomi Perempuan.

- Tim dari Dinas Pengendalian Penduduk, Keluarga Berencana dan Pemberdayaan Perempuan dan Perlindungan Anak Kabupaten Barito Kuala., dengan judul materi Strategi Peremcanan Pembangunan Gender di Kabupaten BATOLA

Hasil dari kegiatan ini bahwa masyarakat khusunya kaum perempuan Pengelola BUMDES

Desa Karang Bunga, Kecamatan Mandastana, Kabupaten Batola-Kalsel sebagian telah memiliki kemampuan dasar tentang kewirausahaan sebagai modal dasar mencari kerja ataupun membuka usaha 
baru, serta terbentuknya komunitas masyarakat untuk membuka usaha baru berbasis potensi lokal yang berwawasan gender.

Foto Dokumentasi Kegiatan :
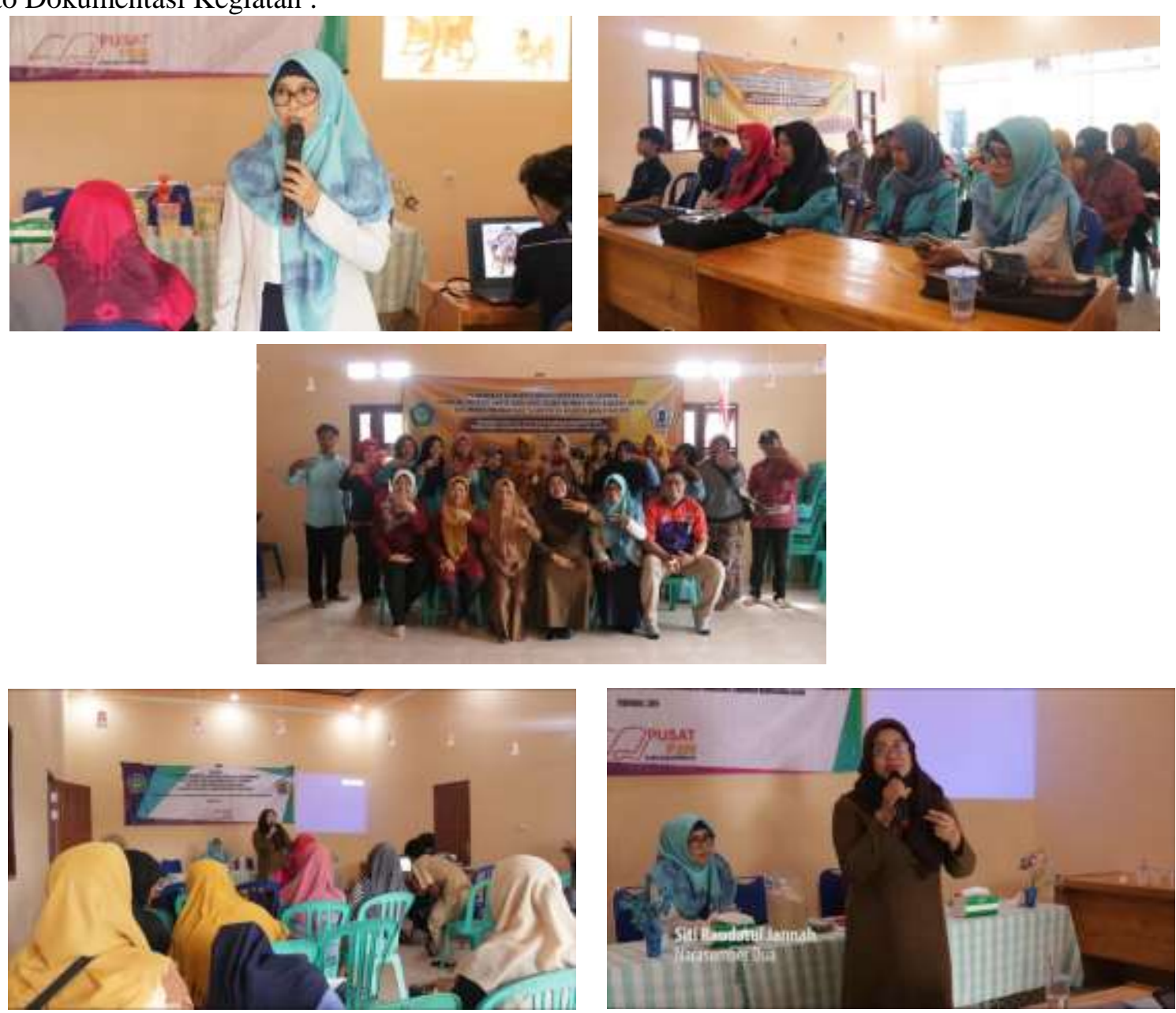

PENUTUP

Kesimpulan

Program pengabdian pada masyarakat ini dapat diselenggarakan dengan baik dan berjalan dengan lancar sesuai dengan rencana kegiatan yang telah disusun meskipun belum semua peserta pendampingan menguasai dengan baik materi yang disampaikan. Kegiatan ini mendapat sambutan sangat baik terbukti dengan keaktifan peserta mengikuti pendampingan dengan tidak meninggalkan tempat sebelum waktu pelatihan berakhir.

\section{Saran}

Berdasarkan evaluasi yang telah dilakukan dapat diajukan beberapa saran sebagai berikut:

1. Waktu pelaksanaan kegiatan pengabdian perlu ditambah agar tujuan kegiatan dapat tercapai sepenuhnya, tetapi dengan konsekuensi penambahan biaya pelaksanaan.

2. Adanya kegiatan lanjutan yang berupa pelatihan sejenis selalu diselenggarakan secara periodik sehinga dapat meningkatkan kemampuan peserta.

\section{DAFTAR PUSTAKA}

Ahmad Suhaimi, 2012, Pengembangan \& Pemberdayaan Masyarakat Konsep Pembangunan Partisipasi Wilayah Pinggiran dan Desa, CV. Budi Utama, Yogyakarta.

David Wijaya, 2018, BUM Desa ( Badan Usaha Milik Desa) Penerbit Gava Media, Yogyakarta. 
BAKTI BANUA : Jurnal Pengabdian Kepada Masyarakat

Volume 1 No. 1 Mei 2020

https://ejurnal.stimi-bjm.ac.id/index.php/BBJM/

Irham Fahmi, 2013, Kewiraushaan Teori, Kasus, dan Solusi, Penerbit Alfabeta, Bandung.

Kementerian PPPA Republik Indonesia-Fak. Ekologi Manusia-IPB PSGA-LPPM IPB, 2015. Modul Pemberdayaan Perempuan One Student Save One Famaly (OSSOF).

Undang-Undang Nomor 7 Tahun 1984 tentang Pengesahan Konvensi Mengenai Penghapusan Segala Bentuk Diskriminasi terhadap Wanita (Lembaran Negara Republik Indonesia Tahun 1984 Nomor 29, Tambahan Lembaran Negara Republik Indonesia Nomor 3277);

Keppres No. 9/2000 tentang Pelaksanaan PUG dalam Pembangunan Nasional;

UU No. 32/2004 tentang Pemda Jo UU No. 23/2014;

Permendagri No. 15/2008 tentang Pedoman umum pelaksanaan PUG di daerah Jo Permendagri No. 67/2011 tentang Pedoman Umum Pelaksanaan PUG di Daerah;

Peraturan Daerah Provinsi Kalimantan Selatan Nomor 3 Tahun 2009 tentang Rencana Pembangunan Jangka Panjang Daerah Provinsi Kalimantan Selatan Tahun 2007-2025;

Perda No. 5/2009 tentang PUG dalam Pembangunan Daerah;

Peraturan Daerah Provinsi Kalimantan Selatan Nomor 11 Tahun 2018 tentang Pemberdayaan Perempuan dan Perlindungan Anak.

\section{Profil Penulis}

1. Nurhikmah, S.H., M.H., M.M. (Dosen) Keilmuan Manajemen SDM, Sekolah Tinggi Ilmu Manajemen Indonesia (STIMI) Banjarmasin, Jl. Kuripan No. 26 Banjarmasin -70123

Email:nurhikmah09dardi@gmail.com

2. Devi Rusvitawati ,S.Pd., M.M.. (Dosen) Keilmuan Manajemen SDM, Sekolah Tinggi Ilmu Manajemen Indonesia (STIMI) Banjarmasin, Jl. Kuripan No. 26 Banjarmasin -70123

Email: devita1412@gmail.com

3. Firda Rezky Herryawan S.St. (Tendik) Keilmuan Manajemen, Sekolah Tinggi Ilmu Manajemen Indonesia (STIMI) Banjarmasin, Jl. Kuripan No. 26 Banjarmasin - 70123

Email: ekylereveur@gmail.com

4. Chumaidi (Mahasiswa) Keilmuan Manajemen, Sekolah Tinggi Ilmu Manajemen Indonesia (STIMI) Banjarmasin, Jl. Kuripan No. 26 Banjarmasin - 70123

Email: chumaidi021@gmail.com

5. MIA (Mahasiswa) Keilmuan Manajemen, Sekolah Tinggi Ilmu Manajemen Indonesia (STIMI) Banjarmasin, J1. Kuripan No. 26 Banjarmasin - 70123

Email: miaarasyid98@gmail.com

6. Tiara Agustina (Mahasiswa) Keilmuan Manajemen, Sekolah Tinggi Ilmu Manajemen Indonesia (STIMI) Banjarmasin, Jl. Kuripan No. 26 Banjarmasin - 70123

Email: tiaraagus1998@gmail.com 